\title{
Review \\ The present and future role of bisphosphonates in the management of patients with breast cancer
}

\author{
Janet E Brown and Robert E Coleman
}

Yorkshire Cancer Research Academic Unit of Clinical Oncology, Cancer Research Centre, Weston Park Hospital, Sheffield, UK

Correspondence: Robert E Coleman, Yorkshire Cancer Research Academic Unit of Clinical Oncology, Cancer Research Centre, Weston Park Hospital, Sheffield S10 2SJ, UK. Tel: +44 114226 5202; fax: +44 114226 5678; e-mail: R.E.Coleman@Sheffield.ac.uk

Received: 28 August 2001

Revisions requested: 19 September 2001

Revisions received: 2 October 2001

Accepted: 22 October 2001

Published: 26 November 2001
Breast Cancer Res 2002, 4:24-29

(C) 2002 BioMed Central Ltd

(Print ISSN 1465-5411; Online ISSN 1465-542X)

\begin{abstract}
At least $25 \%$ of patients with breast cancer develop skeletal metastases, with bone the site of disease producing the greatest morbidity. It is apparent that the bisphosphonates present an important component of the treatment strategy. They are now the treatment of choice in tumour-induced hypercalcaemia, and they can reduce bone pain and skeletal complications such as pathological fractures. In addition, bisphosphonates are being increasingly evaluated in the prevention of bone metastases and to prevent and treat cancer therapy-induced osteoporosis. Ongoing research is aimed at trying to define the optimum route, dose, schedule and type of bisphosphonate.
\end{abstract}

Keywords: bisphosphonates, breast cancer, cancer-induced bone disease

\section{Introduction}

At least $25 \%$ of patients with breast cancer develop skeletal metastases, with bone the site of disease producing the greatest morbidity. Skeletal complications include hypercalcaemia, pathological fracture, bone pain requiring radiotherapy, and spinal cord or nerve root compression. Randomised trials in advanced breast cancer have shown that one of these major events occurs, on average, every 3-4 months $[1,2]$. The average life expectancy from diagnosis of bone metastases is 2 years, with up to $20 \%$ of patients surviving 5 years. There is thus a real need for treatment to reduce skeletal complications and to improve the quality of life in these individuals.

Bone is not an inert organ; normal bone undergoes a continuous process of resorption and formation. Recent research has begun to shed new light on the development of bone metastases, as well as on the continual interaction between cancer cells and active bone. Tumour cells in the bone marrow cavity secrete a variety of paracrine factors that stimulate bone formation. Of key importance is the stimulation of osteoclast function. This results in osteolysis, which is typically associated with disruption of the normal coupling signals that control the relative levels of osteoblast and osteoclast function. It is in this situation that bisphosphonates are able to offer their therapeutic potential in metastatic disease. These abnormalities in bone function are reflected in abnormal levels of serum and urinary collagen breakdown products, which may therefore be exploited as biochemical markers to monitor progress of the disease and the effectiveness of bisphosphonate therapy.

The breast cancer patient with skeletal metastases now has a much improved range of management options, including radiotherapy and radiopharmaceuticals, orthopaedic surgery and systemic anticancer therapy with cytotoxic and endocrine therapy [3]. Nevertheless, it is now apparent that the bisphosphonates present an important additional treatment strategy that can reduce both the symptoms and complications of bone metastases.

\section{Bisphosphonates used in oncology}

All bisphosphonates contain a phosphorus-carbon-phosphorus central structure that promotes their binding to the bone matrix, and variable side chains that determine the specific effects on bone cells. Although a large number of 
candidate compounds are potentially available, and there is continuing interest in the development of new compounds, a relatively small number of bisphosphonates have so far been introduced into routine clinical use in oncology practice. Clodronate (usually given by mouth) and pamidronate (by intravenous infusion) are the two drugs most commonly prescribed for oncological indications.

It is known that less than $5 \%$ of the dose of oral clodronate is absorbed (Fig. 1) [3] and this leads to problems in compliance (taking the size and number of capsules required to maintain a therapeutic dose). A significant proportion of patients also experience gastrointestinal toxicity, which is more common than with intravenous preparations. Infusion of pamidronate typically takes 1-2 hours, placing additional demands on already overworked intravenous therapy units.

Clinical trials with two relatively new bisphosphonates, zoledronic acid and ibandronate, suggest that they may soon find a place in routine therapy. Zoledronic acid, which is given intravenously, shows much greater potency than the earlier bisphosphonate drugs in vitro, and infusion times are dramatically reduced $(15 \mathrm{~min})$. Zoledronic acid has yielded impressive results in the treatment of hypercalcaemia and bone pain associated with bone metastases [4], and is at least as effective as pamidronate in the prevention of skeletal morbidity from breast cancer $[5,6]$.

lbandronate is an amino-bisphosphonate that is also highly potent and is now licensed in Europe for the treatment of hypercalcaemia of malignancy. Ibandronate also appears to offer benefit in the treatment and prevention of osteoporosis, and in reduction in skeletal morbidity in metastatic bone disease [7]. As well as the intravenous form, an oral preparation is being developed that appears to be well tolerated at a therapeutically useful dose [8].

\section{The use of bisphosphonates in tumour-induced hypercalcaemia}

Hypercalcaemia is the most common metabolic complication of malignancy and it is important to recognise because it is associated with a range of unpleasant gastrointestinal and neurological side effects. Hypercalcaemia frequently responds well to treatment, at least in the short term, which can significantly improve a patient's quality of life.

The pathophysiology depends on several factors including local osteolysis by tumour cells and more generalised osteolysis by humoral factors. Parathyroid hormone related protein levels are often raised in patients with hypercalcaemia and appear to have an important role in humoral hypercalcaemia of malignancy [9]. Renal effects, including increased renal tubular reabsorption of calcium and impaired renal glomerular filtration, also contribute [3].
Figure 1

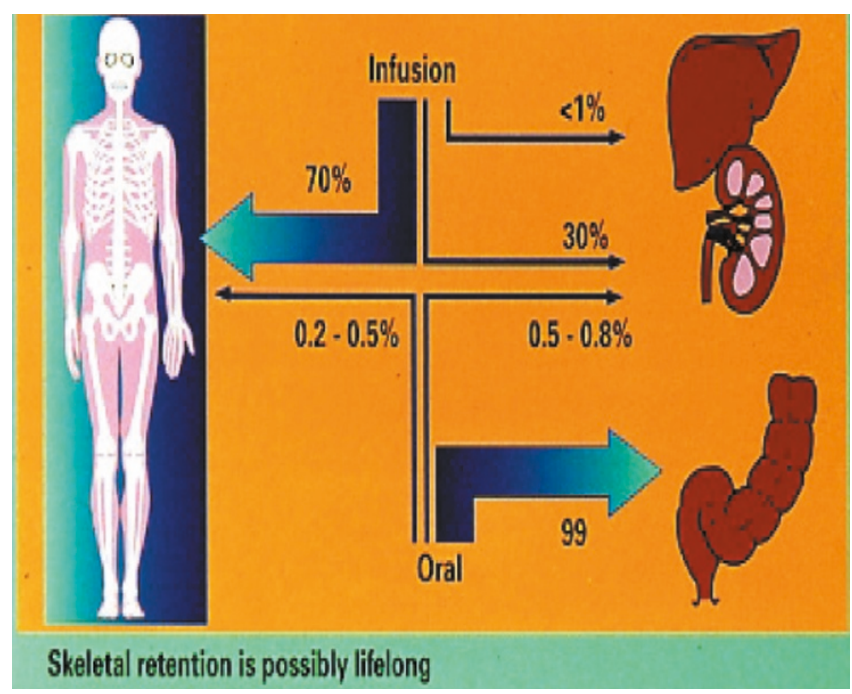

Pharmacokinetics of bisphosphonates showing the skeletal retention and poor oral availability of currently available compounds.

Bisphosphonates, since their introduction, have revolutionised the treatment of hypercalcaemia, and an intravenous bisphosphonate together with rehydration is now the standard treatment of hypercalcaemia of malignancy. Generally, bisphosphonates need to be given intravenously to allow restoration of normocalcaemia, although clodronate can be given subcutaneously and this can be useful in the pallative care setting. Intravenous clodronate as a single infusion of $1500 \mathrm{mg}$ can achieve normocalcaemia in $80 \%$ of patients [9]. Similar studies with pamidronate given as a single infusion over 2-24 hours have shown that normocalcaemia can be achieved in up to $90 \%$ of patients [9].

Newer and potentially more potent bisphosphonates such as zoledronic acid may be even more effective and, because of their shorter infusion time, may simplify treatment. A recent pooled analysis of two randomised, controlled trials compared intravenous zoledronic acid (doses of 8 and $4 \mathrm{mg}$ ) with pamidronate $(90 \mathrm{mg})$ in hypercalcaemia of malignancy [4]. After 10 days, both zoledronic acid arms of the trial showed a better complete response rate ( $8 \mathrm{mg}, 88.4 \% ; 4 \mathrm{mg}, 86.7 \%$ ) compared with the pamidronate arm (69.7\%). The response duration was also better in the zoledronic acid arms of the trial (43 and 32 days) compared with the pamidronate arm (18 days).

\section{Bisphosphonates for bone pain}

External beam radiotherapy remains the treatment of choice for many patients with well-localised bone pain, 
with excellent results achieved in most situations with a short treatment schedule of one to five fractions. However, patients often have widespread, poorly localised, nonmechanical pain, and other patients experience recurrent pain in previously irradiated sites. For this group of patients, bisphosphonates provide a useful alternative treatment option.

Most experience with bisphosphonates for bone pain is from their use for skeletal metastases in advanced breast cancer, although the effects of bisphosphonates on pain seem to be independent of the nature of the underlying tumour or radiographic appearance of the metastases, with sclerotic lesions responding similarly to lytic metastases. Studies with the currently available oral bisphosphonates (at doses tested) have been disappointing; none have convincingly been shown to alleviate metastatic bone pain in a clinically significant manner $[9,10]$ in the absence of systemic anticancer therapy. To obtain a useful effect, the intravenous route is necessary at least until more potent oral formulations are available. Several studies using intravenous clodronate, ibandronate, pamidronate and zoledronic acid have all demonstrated useful pain relief with improvements in analgesia requirements and an improved quality of life $[7,9,11]$.

A randomised, double-blind trial to evaluate the contribution of markers of bone resorption in patients with bone metastases was carried out by Vinholes et al. [12]. Symptomatic decrease in bone pain was seen after administration of pamidronate but not placebo, and the response correlated well with a decrease in bone resorption markers, particularly $\mathrm{Ntx}$ ( $\mathrm{N}$-terminal telopeptide of type I collagen). It appeared to be necessary to normalise bone resorption markers to achieve optimal pain relief and this should be the aim of bisphosphonate therapy. Those individuals who had an initial level of bone resorption markers greater than twice the upper normal limit responded very poorly to pamidronate and this may have useful predictive value for therapy.

Two recent studies have highlighted the apparent advantage of intravenous over oral bisphosphonates in pain reduction. A study by Diel et al. [13] over a period of 2 years with 361 patients treated with oral clodronate, intravenous clodronate, or intravenous pamidronate showed the best pain reduction was achieved by intravenous therapy. In a study in our own centre, 51 patients with metastatic bone disease were randomly allocated to treatment with oral clodronate, intravenous clodronate followed by the same schedule of oral clodronate, or intravenous pamidronate. There was a significantly greater improvement in pain scores in the intravenous pamidronate arm of the trial, and this was reflected in an accompanying improvement in bone resorption markers [10].
The optimum dose and choice of bisphosphonate may depend on the stage of the disease, and individual response in bone markers may play an increasingly important role in the future in tailoring treatment to the individual patient.

\section{The use of bisphosphonates in limiting skeletal complications of bone metastases}

There is now overwhelming evidence that bisphosphonate therapy reduces skeletal complications in breast cancer, such that it should now be considered part of standard cancer therapy. Data from some of the many clinical trials to assess the effects of bisphosphonates (particularly clodronate and pamidronate) on skeletal-related events are summarised in Table 1.

Randomised trials comparing chemotherapy + pamidronate with chemotherapy + placebo were particularly striking, with a significant reduction in the mean number of skeletal related events per year in the pamidronate arm of the trials $[14,15]$. Such trials also demonstrated that a reduction in skeletal morbidity began to be apparent after 3 months of treatment with bisphosphonates and was maintained throughout the study period. In addition, quality of life was maintained and a reduction in pain and analgesic use was observed compared with the placebo group. In one study by Hortobagyi et al. [2] there was a significant reduction in the proportion of patients having any skeletal related events (43\% versus 56\%), a reduction in the number of non-vertebral pathological fractures (by 60\%), and a reduction in the proportion of patients having radiation to bone (by $45 \%$ ) or surgery on bone (by $52 \%$ ).

These trials led to the worldwide registration of pamidronate for treatment of metastatic breast cancer. A randomised, double-blind, dose-finding phase II study of zoledronic acid [5] has led to a phase III study using 4-8 mg for the treatment of osteolytic metastases, including breast cancer, the results of which are awaited.

In patients with metastatic breast cancer, bisphosphonates have not yet shown any significant overall effects on patient survival, although subgroup analyses have suggested that young ( $<50$ years) patients with breast cancer receiving chemotherapy may gain a small survival advantage $[1,16]$.

Recent research has focused on optimising the treatment parameters. Of particular importance is the need for trial evidence regarding the most appropriate time to initiate bisphosphonate treatment and its optimum duration. It would be extremely useful to be able to predict whether a particular patient is likely to respond to bisphosphonate treatment. It seems possible that biochemical markers of bone resorption may be useful in this respect, and there is evidence that patients who fail to normalise bone resorption markers experience a higher number of skeletal events. 
Table 1

\begin{tabular}{|c|c|c|c|}
\hline Agent and route & $n$ & Results (no bisphosphonate versus bisphosphonate treated) & Reference \\
\hline Pamidronate, $600 \mathrm{mg}$ orally daily & 161 & $\begin{array}{l}\text { Reduced SMR, } 94 \text { vs } 52 \text { events } / 100 \text { women years }(P<0.01) \\
600 \text { mg poorly tolerated; no benefit with reduced dose }(300 \mathrm{mg})\end{array}$ & van Holten-Verzantvoort et al. [24] \\
\hline Clodronate, $1600 \mathrm{mg}$ orally daily & 173 & Reduced SMR, 305 vs 219 events $/ 100$ woman years $(P<0.001)$ & Paterson et al. [25] \\
\hline $\begin{array}{l}\text { Pamidronate, } 45 \mathrm{mg} \text { intravenously } \\
3 \text { weekly }\end{array}$ & 295 & Increased time to bone progression, 168 vs 249 days $(P=0.02)$ & Conte et al. [14] \\
\hline $\begin{array}{l}\text { Pamidronate, } 90 \mathrm{mg} \text { intravenously } \\
3-4 \text { weekly }\end{array}$ & 382 & $\begin{array}{l}\text { Reduced proportion experiencing SRE, } 65 \text { vs } 46 \%(P<0.001) \\
\text { Delay in first SRE, } 7.0 \text { vs } 13.1 \text { months }(P=0.0005)\end{array}$ & Hortobagyi et al. [2] \\
\hline $\begin{array}{l}\text { Pamidronate, } 60 \mathrm{mg} \text { intravenously } \\
\text { monthly }\end{array}$ & 401 & $\begin{array}{l}\text { Increased median time to skeletal progression, } \\
9 \text { vs } 14 \text { months }(P<0.01)\end{array}$ & Hultborn et al. [15] \\
\hline $\begin{array}{l}\text { Pamidronate, } 90 \mathrm{mg} \text { intravenously } \\
3-4 \text { weekly }\end{array}$ & 374 & $\begin{array}{l}\text { Reduced proportion experiencing SRE, } 67 \text { vs } 56 \%(P=0.027) \\
\text { Delay in first SRE, } 6.9 \text { vs } 10.4 \text { months }(P=0.049)\end{array}$ & Theriault et al. [1] \\
\hline $\begin{array}{l}\text { Ibandronate, } 2 / 6 \mathrm{mg} \text { intravenously } \\
3-4 \text { weekly }\end{array}$ & 467 & $\begin{array}{l}\text { Reduced SMR with } 6 \mathrm{mg} \text { dose; } 2 \mathrm{mg} \text { ineffective } \\
\text { SMR, } 2.18 \text { vs } 1.61 \text { events } / 100 \text { women years }(P=0.03)\end{array}$ & Body et al. [9] \\
\hline
\end{tabular}

$\mathrm{SRE}=$ skeletal related events; $\mathrm{SMR}=$ skeletal morbidity rate.

In one study of 21 patients with raised bone markers receiving pamidronate [17], 12 patients normalised the rate of bone resorption. The normalised group showed a significant reduction in progression of their skeletal metastases $(P=0.03)$, compared with the remaining nine patients whose bone resorption remained abnormal. In the group that normalised, there was also a reduction in fracture rate that approached, but did not reach, significance $(P=0.07)$ in this small study.

\section{Osteoporosis in cancer patients}

There are now increasing numbers of long-term survivors who have received combination chemotherapy, radiotherapy and hormonal cancer treatment. Many of these individuals are at increased risk of osteoporosis, largely because of the endocrine changes induced by such therapy. This is a particularly important long-term problem in women with breast cancer for whom there are concerns about the safety of hormone replacement therapy. In such patients, bisphosphonates represent an effective alternative therapy both to prevent and to treat osteoporosis, and biphosphonates should be seriously considered particularly in those experiencing an early menopause [18].

\section{Prevention or delay of bone metastases}

Since the release of growth factors and cytokines from resorbing bone are known to facilitate cancer cell growth and proliferation at the bone surface, the known effects of bisphosphonates in reducing bone resorption might be expected to inhibit initiation and progression of metastatic bone disease. After encouraging animal studies, several human trials have been carried out with the bisphosphonate clodronate. The clinical benefit is far from clear at present, however, due to apparently conflicting results. In a study of 1079 women with primary operable breast cancer, only 28 (5.2\%) patients on clodronate developed definite bone metastases compared with 44 (8.1\%) on placebo, with a mean follow-up of 4 years $(P=0.054)$ [19].

Diel et al. [20] studied a group of 302 primary breast cancer patients who had no overt evidence of metastatic disease but who had tumour cells in the bone marrow, a risk factor for development of distant metastases. Patients were randomly assigned to receive oral clodronate for 2 years (157 patients) or standard follow-up (145 patients). The median observation period was 36 months. The incidence of osseous metastases was significantly lower in the clodronate group (11 patients versus 25 patients; $P<0.002$ ) and there was also an unexpected reduction in the incidence of visceral metastases in the clodronate group (19 patients versus 42 patients; $P<0.001)$.

This potentially exciting finding must, however, be viewed in the light of a further trial that suggested quite the reverse. Saarto et al. [21] randomised a group of 299 women with primary node-positive breast cancer to clodronate (149 patients) and to control (150 patients), with a follow-up of 5 years for all patients. Bone metastases were detected equally often in the clodronate group (29 patients) and the control group (24 patients) $(P=0.27)$, the development of non-skeletal recurrence was significantly higher in the clodronate group (60 patients versus 36 patients; $P=0.0007$ ) and, most importantly, the overall survival was significantly lower in the clodronate group (70\% versus $83 \% ; P=0.009$ ).

Identifying a definite adjuvant role for bisphosphonates will therefore require further large, randomised studies to resolve these and other issues. Until the results of further 
trials that are currently under way with zoledronic acid, clodronate and ibandronate are available, the routine use of bisphosphonates in the adjuvant setting outside of research trials is not currently recommended except for prevention or treatment of osteoporosis.

\section{Conclusions and the future}

There is now a much greater appreciation of the benefits of active management of metastatic bone disease and the options for doing so. Indeed, the success of bisphosphonates has focused attention on the mechanisms of the control of bone metabolism in cancer and this is leading to a search for new agents that might act as osteoclast inhibitors.

One promising compound is osteoprotegerin, which is a member of the tumour necrosis factor receptor super family and is a natural inhibitor of osteoclast production and activity. Osteoprotegerin acts as a decoy receptor, binding with osteoprotegerin ligand (the natural stimulator of osteoclast maturation) produced by the osteoblast [22]. Very recent studies in mice have shown that osteoprotegerin halted further bone damage and diminished the skeletal pain associated with tumour-induced bone destruction [23]. A synthetic preparation showed promising effects on bone resorption in normal volunteer testing (Amgen data on file). If this promise is confirmed by phase I clinical trials in cancer patients that are currently under way, this long-acting, subcutaneous preparation could have an important therapeutic role in the future.

Bisphosphonates have now been accepted as the treatment of choice in hypercalcaemia of malignancy and have an important role in reducing skeletal-related events, in reducing bone pain and in associated analgesic use, as well as improving quality of life. Bisphosphonates should therefore now be considered as standard treatment in metastatic bone disease from breast cancer. Further research is needed to determine the best time to start treatment, but once treatment has commenced it should be continued for as long as the skeleton is the dominant site of metastasis. The future may see further developments in the range of bisphosphonates available as well as the use of biochemical markers to tailor treatment to individual patients.

\section{References}

1. Theriault RL, Lipton A, Hortobagyi GN, Leff R, Gluck S, Stewart JF, Costello S, Kennedy I, Simeone J, Seman JJ, Knight RD, Mellars K, Heffernan M, Reitsma DJ: Pamidronate reduces skeletal morbidity in women with advance breast cancer and lytic bone lesions: A randomised, placebo-controlled trial. J Clin Oncol 1999, 17:846-854.

2. Hortobagyi GN, Theriault RL, Porter L, Blayney D, Lipton A, Sinoff $\mathrm{C}$, Wheeler H, Simeone JF, Seaman J, Knight RD: Efficacy of pamidronate in reducing skeletal complications in patients with breast cancer and lytic bone metastases. $N$ Engl J Med 1996, 335:1785-1791.

3. Coleman RE, Management of bone metastases. The Oncologist 2000, 5:463-470.
4. Major P, Lortholary A, Hon J, Abdi E, Mills G, Menssen HD, Yunus $F$, Bell R, Body J, Quebe-Fehling E, Seaman J: Zoledronic acid is superior to pamidronate in the treatment of hypercalcemia of malignancy: A pooled analysis of two randomised, controlled clinical trials. J Clin Oncol 2001, 19:558-567.

5. Berenson JR, Rosen LS, Howell A, Porter L, Coleman RE, Morley W, Dreicer R, Kuross SA, Lipton A, Seaman JJ: Zoledronic acid reduces skeletal related events in patients with osteolytic metastases: a double-blind, randomised dose-response study. Cancer 2001, 91:1191-1200.

6. Coleman R, Apffelstaedt J, Major P, Mackey J, Howell A, Theriault $\mathrm{R}$, Gordon D, Ambros Y: Zometa is equivalent to pamidronate in the prevention of skeletal related events secondary to metastatic breast cancer treated with hormonal therapy [abstract]. Eur J Cancer 2001, 37(6):S152.

7. Body JJ, Lichinitser MR, Diehl IE, Schlosser K, Pfarr E, Cavalli V, Dornoff V, Gorbuova VA, McCloskey E, Weiss J, Kanis JA: Double-blind placebo controlled trial of ibandronate in breast cancer metastatic to bone [abstract]. Proc ASCO 1999, 18:575a.

8. Coleman RE, Purohit OP, Black C, Vinholes JJ, Schlosser K, Huss $\mathrm{H}$, Quinn KJ, Kanis J: Double-blind, randomised, placebo-controlled study of oral ibandronate in patients with metastatic bone disease. Ann Oncol 1999, 10:311-316.

9. Body JJ, Bartl R, Burckhardt P, Delmas PD, Diel IJ, Fleish H, Kanis JA, Kyle RA, Mundy GR, Paterson AH, Rubens RD: Current use of bisphosphonates in oncology. International Bone and Cancer Study Group. J Clin Oncol 1998, 16:3890-3899.

10. Jagdev SP, Purohit OP, Heatley S, Herling C, Coleman RE: Comparison of the effects of intravenous pamidronate and oral clodronate on symptoms and bone resorption in patients with metastatic bone disease. Ann Oncol 2001 (in press).

11. Berenson JR, Lipton A, Rosen LS: Phase I clinical study of a new bisphosphonate, zoledronate (CGP-42446), in patients with osteolytic bone metastases [abstract]. Blood 1998, 88(suppl 1):586a.

12. Vinholes JJ, Purohit OP, Abbey ME, Eastell R, Coleman RE: Relationships between biochemical and symptomatic response in a double-blind trial of pamidronate for metastatic bone disease. Ann Oncol 1997, 8:1243-1250.

13. Diel IJ, Marschner N, Kindler M, Lange O, Untch M, Hurtz HJ, Breitbach GP, Richter B: Continual oral versus intravenous interval therapy with bisphosphonates in patients with breast cancer and bone metastases [abstract]. Proc ASCO 1999, 18:128.

14. Conte PF, Latreille J, Mauriac L, Calabresi F, Santos R, Campos $D$, Bonneterre J, Francini G, Ford JM: Delay in progression of bone metastases treated with intravenous pamidronate: Results from a multicentre randomised controlled trial. $J$ Clin Oncol 1996, 14:2552-2559.

15. Hultborn R, Ryden S, Gunderson S, Holmberg E, Wallgren U-B: Efficacy of pamidronate on skeletal complications from breast cancer metastases. A randomised prospective double blind placebo controlled trial. Acta Oncol 1996, 35(suppl 5): 73-74.

16. Lipton A, Theriault RL, Hortobagyi GN, Simeone J, Knight RD, Mellars K, Reitsma DJ, Heffernan M, Seamann JJ: Pamidronate prevents skeletal complications and is effective palliative treatment in women with breast cancer and osteolytic bone metastases: long-term results of two randomised, placebocontrolled trials. Cancer 2000, 88:1082-1090.

17. Lipton A, Demers L, Curley E, Chinchilli V, Gaydos L, Hortobagyi G, Theriault R, Clemens D, Costa L, Seaman J, Knight R: Markers of bone resorption in patients treated with pamidronate. Eur J Cancer 1998, 34:2021-2026.

18. Fontana A, Delmas PD: Osteoporosis in cancer patients. In Cancer and the Skeleton. Edited by Rubens RD, Mundy GR. London: Martin Dunitz Ltd; 2000:263-270.

19. Powles TJ, Paterson AHG, Nevantaus A, Legault $S$, Pajunen $M$, Tidy VA, Rosenquist K, Smith IE, Ottestad L, Ashley S, Walsh G, McCloskey E, Kanis JA: Adjuvant clodronate reduces the incidence of bone metastases in patients with primary operable breast cancer [abstract]. Proc ASCO 1998, 17:468.

20. Diel I, Solomayer EF, Costa SD, Gollan C, Goerner R, Wallwiener $D$, Kaufmann M, Bastert G: Reduction in new metastases in breast cancer with adjuvant clodronate treatment. $N$ Engl J Med 1998, 339:357-363. 
21. Saarto T, Blomqvist C, Virkkunen P, Eloma A: Adjuvant clodronate treatment does not reduce the frequency of skeletal metastases in node-positive breast cancer patients: 5-year results of a randomized controlled trial. J Clin Oncol 2001, 19: 10-17.

22. Kong YY, Yoshida H, Sarosi I, Tan HL, Timms E, Morony $S$, Oliveira-dos-Santos AJ, Van G, Itie A, Khoo W, Wakeham A, Dunstan CR, Lacey DI, Mak TW, Boyle WJ, Penninger JM: OPGL is a key regulator of osteoclastogenesis, lymphocyte development and lymph-node organogenesis. Nature 1999, 397:315323.

23. Honore $P$, Luger NM, Sabino AC, Schwei MJ, Rogers SD, Mach DB, O'Keefe PF, Ramnaraine ML, Clohisy DR, Mantyh PW: Osteoprotogerin blocks bone cancer-induced skeletal destruction. Skeletal pain and pain-related neurochemical reorganisation of the spinal cord. Nat Med 2000, 6:521-528.

24. van Holten-Verzantvoort AT, Bijvoet OLM, Cleton FJ, Hermans J, Kroon HM, Harinck HI, Vermey P, Elte JW, Neijt JP, Beex LV: Reduced morbidity from skeletal metastases in breast cancer patients during long term bisphosphonate (APD) treatment. Lancet 1987, ii:983-985.

25. Paterson AHG, Powles TJ, Kanis JA, McCloskey E, Hanson J, Ashley S: Double-blind controlled trial of oral clodronate in patients with bone metastases from breast cancer. J Clin Oncol 1993, 11:59-65. 